\title{
Intrathecal morphine reduces immediate pain after lumbar arthrodesis
}

\author{
H.Kamga; F.Lucas; JL Hanouz CHU Caen, France
}

\section{Introduction}

Several studies have demonstrated intrathecal morphine (IM) efficacy in reducing pain after Lumbar arthrodesis (LA). None has addressed pain in the recovery room. The aim of this study is to evaluate the efficacy of IM on pain in recovery room.

\section{Material and methods}

This is a retrospective single center study from November 2016 to January 2012. The patients operated for LA were classified in IM group and no IM group. The regimen of IM and multimodal analgesia were decided by the attending anesthesiologist. The main outcome was the proportion of patient requiring morphine titration in recovery room. The secondary ends points were the rate of adverse effect of IM.

\section{Results}

The characteristics of the patients and the surgery are shown in table 1 . The rates of morphine titration in recovery room are shown in figure 1 . No adverse effect occurred in recovery room.

Table 1: characteristics of patients

\begin{tabular}{|c|c|c|c|}
\hline & Intrathecal morphine & No intrathecal morphine & $\mathbf{p}$ \\
\hline Number of patients (431) & $129(30 \%)$ & $302(70 \%)$ & \\
\hline Sex ratio & 0.88 & 0.75 & 0.50 \\
\hline Age (years) & $57(13) *$ & $58+/-14$ & 0.41 \\
\hline Arthrodesis with interbody fusion & $44 \%$ & $40 \%$ & 0.52 \\
\hline Number of level & $1[1 ; 2] \#$ & $1[1 ; 2]$ & 0.05 \\
\hline Dose of IM $(\mu \mathrm{g})$ & $200[100 ; 300] \#$ & & \\
\hline ASA status & $2[2 ; 3] \#$ & $2[2 ; 3]$ & 0.68 \\
\hline Length of surgery (minutes) & $189(73) *$ & $171(62)$ & 0.02 \\
\hline Blood losses (ml) & $250[150 ; 400] \#$ & $250[100 ; 500]$ & 0.48 \\
\hline NRPS in recovery room & $0[0 ; 8] \#$ & $6[1 ; 8]$ & $<0.0001$ \\
\hline
\end{tabular}

* Mean and standard deviation. \# Median and interquartile. NRPS : Numeric rating pain scale.

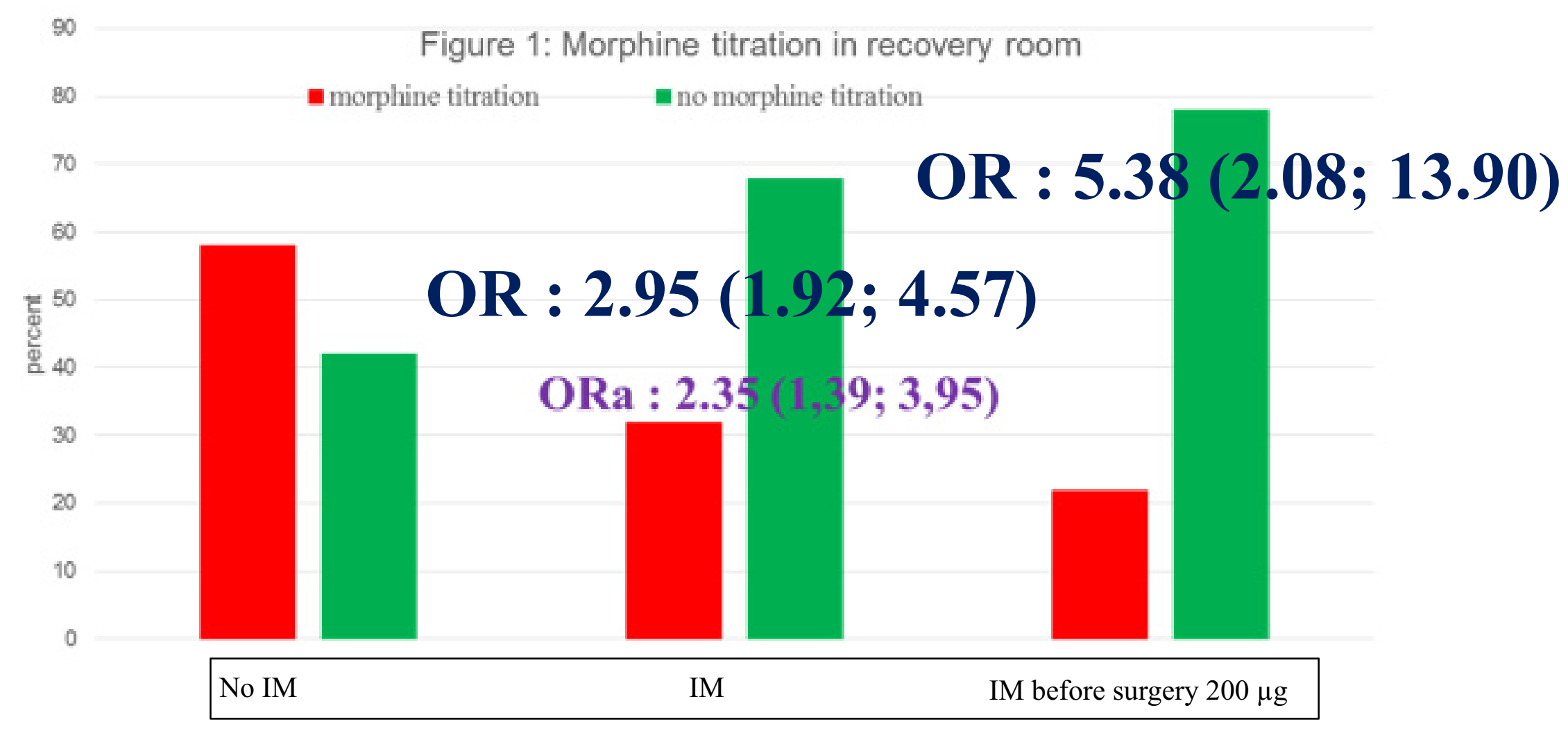

\section{Discussion}

IM reduces the need of morphine in recovery room. This is more prominent when the IM is administrated before surgery at the dose of $200 \mu \mathrm{g}$. Usually, for LA, IM is administrated by the surgeon at the end of surgery with an efficiency up to four hours after surgery (1). The median dose of IM was $200 \mu \mathrm{g}$ with no adverse effect in recovery room. Boezaart and al has demonstrated the safety of dose up to $300 \mu \mathrm{g}(2)$.

\section{Conclusion}

IM may reduce the need of morphine in the recovery room after LA. IM should be administrated before surgery at the dosage of $200 \mu \mathrm{g}$. 